\title{
Exhibitions of Soviet fine art in 1930 in the reviews of the foreign press
}

\author{
S. S. Bakaryagin ${ }^{1}$
}

${ }^{1}$ P. G. Demidov Yaroslavl State University, 14 Sovetskaya str., Yaroslavl 150003, Russian Federation

DOI: $10.18255 / 1996-5648-2021-4-498-505$

Research article Full text in Russian

The article examines the reviews of the German, Austrian and Swedish periodicals about some exhibitions of Soviet fine art held in 1930. On the basis of archival materials, the attitude of the foreign press to the Soviet exhibition projects in Berlin, Vienna and Stockholm is analyzed. The influence of the political orientation of periodicals on the assessment of the plots of the works of Soviet artists is emphasized. When characterizing the painting technique and compositional structure of the works, critics pointed to their continuity from the Western European tradition. Soviet graphics and sculpture made a positive impression. Critics associated the artistic successes mainly with the masters of the old Russian school.

Keywords: exhibition; artists; newspaper; art; critique; abroad

\section{INFORMATION ABOUT AUTHORS}

\begin{tabular}{l|l} 
Bakaryagin, Stepan S. & $\begin{array}{l}\text { E-mail: stepan280694@yandex.ru } \\
\text { Postgraduate }\end{array}$
\end{tabular} 


\section{Выставки советского}

изобразительного искусства 1930 г.

в отзывах зарубежной прессы

\section{С. С. Бакарягин ${ }^{1}$}

${ }_{1}^{1}$ Ярославский государственный университет им. П. Г. Демидова, ул. Советская, 14, Ярославль, 150003, Российская Федерация

DOI: 10.18255/1996-5648-2021-4-498-505

УДК 930.85

Научная статья

Полный текст на русском языке

В статье рассматриваются отзывы немецкой, австрийской и шведской периодической печати о некоторых выставках советского изобразительного искусства, проведенных в 1930 г. На основе архивных материалов анализируется отношение зарубежной прессы к советским выставочным проектам в Берлине, Вене и Стокгольме. Подчеркивается влияние политической направленности периодических изданий на оценку сюжетов произведений советских художников. При характеристике живописной техники и композиционной структуры работ критики указывали на связь с западноевропейской традицией. Положительное впечатление произвела советская графика и скульптура. Живописные успехи критики связывали преимущественно с мастерами старой русской школы.

Ключевые слова: выставка; художники; газета; искусство; критика; зарубежье

\section{ИНФОРМАЦИЯ ОБ АВТОРАХ}

Бакарягин, Степан Сергеевич $\mid$ E-mail: stepan280694@yandex.ru

Аспирант

Постепенный выход Советской России из политической изоляции в начале 1920-х гг. сопровождался ростом культурного сотрудничества с зарубежьем. Взаимодействие в сорере культуры служило своего рода катализатором, смягчающим напряженные и не отличающиеся доверием отношения между молодой республикой, странами Запада и русской эмиграцией [1]. Оно было призвано продемонстрировать за границей, что искусство в стране Советов не уничтожено, а продолжает активно развиваться в условиях новых исторических реалий.

Во второй половине 1920-х гг., после создания Всесоюзного общества культурных связей с зарубежьем (ВОКС), международные взаимоотноше(c) Бакарягин С. С., 2021

Статья открытого доступа под лицензией CC BY (https://creativecommons.org/licenses/by/4.0/) 
Бакарягин С. С.

ния вышли на новый уровень. 8 августа 1925 г. Советом народных комиссаров (СНК) СССР был принят устав ВОКСа. В нем значилось, что целью создания организации являлось “установление научной и культурной связи между учреждениями, общественными организациями и отдельными научными и культурными работниками Союза ССР и заграницы» [2]. Чуть позже стали издавать специальный бюллетень на трех языках, призванный «не только сообщать, но и главным образом пропагандировать» достижения советской культуры, соблюдая при этом, насколько возможно, нейтральный тон. ВОКС выступала инициатором целого ряда выставок, которые знакомили иностранного зрителя с советской культурой. За период 1928-1931 гг. Всесоюзным обществом культурных связей было организовано 189 выставок в странах Европы (Германия, Австрия, Италия и др.), США, Канаде, Японии, странах Латинской Америки и Востока. В свою очередь, 28 выставок западного искусства было представлено в Советском Союзе $[3$, c. 58,60$]$.

Столь энергичная выставочная деятельность СССР получила широкий резонанс в зарубежной прессе. Материалы Российского государственного архива литературы и искусства (РГАЛИ) содержат переведенные на русский язык выписки из европейских периодических изданий 1930 г., таких, например, как германские "Vossische Zeitung», «Die Rote Fahne», австрийские «Das interessante Blatt», «Reichspost» и целый ряд других газет и журналов. В этих документах имеются сведения о реакции части иностранной публики на выставки советского искусства в Берлине, Вене и Стокгольме. Европейские художественные критики, как правило, старались провести параллель между советским искусством и творчеством своих соотечественников, стремясь оценить характер изобразительного искусства в СССР, его идейную и художественную новизну [4-6]. Переводы шведской прессы, в отличие от немецкой и австрийской, по всей вероятности, осуществлялись другим ведомством, из-за чего оказалось затруднительно установить полное название газеты и, следовательно, ее идеологическую платформу. В связи с этим наименования периодической печати Стокгольма в данной статье приводятся на русском языке. Кроме указанных материалов, мы можем встретить упоминания о подготовке и устройстве советских экспозиций в Нью-Йорке, Венеции, Праге и Кельне [7].

Статьи и отзывы зарубежных критиков рассматривались в заметках А. В. Луначарского о выставках в Берлине и Венеции. Сам он еще до революции плодотворно работал в области художественной критики и уже на посту народного комиссара просвещения в 1917-1929 гг. по-прежнему продолжал интересоваться ситуацией в художественном мире. Анализируя заграничную прессу, А. В. Луначарский отмечал влияние политической ориентации тех или иных газет и журналов на отношение к советскому изобразительному искусству [8]. В книге "АХРP» (Ассоциация художников революционной России) приводятся воспоминания А. Н. Тихомирова, которому в свое время доводилось сопровождать художественные произ- 
ведения за границу. Он писал об установлении сотрудничества с зарубежными художниками, о реакции публики (в том числе иностранной прессы) на советские выставки [9].

В данной статье на основе материалов Российского государственного архива литературы и искусства (РГАЛИ) предпринята попытка рассмотреть реакцию зарубежной периодической печати, живо откликнувшейся на некоторые выставочные проекты СССР 1930 года. Главным образом, это касается прессы Германии, Австрии и Швеции, где выставки «большевистских картин» не оставили публику равнодушной. В то же время, по свидетельству современников, периодическая печать не смогла беспристрастно оценить реальное положение дел в советском изобразительном искусстве.

А. В. Луначарский писал: «Несколько более шаток наш успех в прессе; здесь сказалась не только разница во мнениях - от очень хвалебных до очень злобных и даже злостно клеветнических, - но и разлад самих критериев на Западе, о котором мы прекрасно знаем. Ведь и там есть свои «правые», свои «левые» художники и их почитатели, - и выставки, конечно, по-разному преломились в этих различных слоях» [8, с. 118]. И все же, несмотря на противоречивость картины, представленной зарубежной периодической печатью, попытаемся определить тенденции, характерные для восприятия советского искусства на Западе. Так, европейских критиков, в первую очередь волновала сюжетная сторона представленных произведений. Они полагали, что в новом обществе, которое строится на идеях социализма, принципиально новыми должны быть и сюжеты окружающей жизни. В атмосфере ожидаемой сенсации от «большевистских» картин летом 1930 г. в берлинском Сецессионе открылась выставка советского искусства. Торжественное открытие проходило при личном участии бывшего наркома просвещения РСФСР А. В. Луначарского. На выставке были представлены все художественные общества Советского Союза, экспонировались 150 произведений живописи, 100 листов графики, а также скульптура и фраянсовые изделия.

Отзывы зарубежной публики на страницах периодической печати не заставили себя долго ждать. Критик из "Frankfurter Zeitung» (статья «Советская Россия показывает живопись» от 20.07.1930) отмечал, что, к сожалению для себя, не увидел «ни малейшего влияния новой России, коммунистического общества или революции. Видимо, программы могут быть новыми, но искусство - нет» [...]. Он продолжал: «Она (выставка. - С. Б.) столь буржуазна, как этого может пожелать только сторонник буржуазии. Советского искусства, таким образом, не существует» [4, л. 9].

В октябре - ноябре 1930 г. изобразительное искусство СССР было представлено в Австрии. Однако и здесь нашлось место порицанию советских художников за их подход к выбору и трактовке тех или иных сюжетов. Автор статьи «Современное русское искусство» (от 31.10.1930) в «Reichspost» писал: «Не вызвали новых ощущений индустриальные сюжеты и темы рабочих». Было отмечено, что австрийские художники справлялись с подоб- 
Бакарягин С. С.

ными творческими задачами «гораздо лучше - подлинно художественно", а «красными знаменами, стреляющими красноармейцами и наивно-детскими демонстрациями» невозможно проложить дорогу к новому искусству [5, л. 3].

Таким образом, упреки в выборе советскими художниками сюжетов картин нередко были обусловлены тем, что европейский зритель не мог открыть для себя нечто нового по сравнению с увиденным ранее. Иногда присутствовало и неприязненное отношение авторов к советскому строю в целом. В берлинской «Deutsche Allgemeine Zeitung» (от 12.07.1930) заметен откровенно глумливый тон критики: «Посетителя охватывает большая веселость, когда он видит эту офрициальную выставку диктатуры пролетариата. Потому что здесь он находит не только буржуазную, но прямо мещанскую выставку. Скрытые устремления к советскости меняются с «Заседанием Совнаркома», переданным в стиле старых придворных живописцев» [4, л. 8].

В свою очередь, критиков, симпатизирующих стране Советов и публикующихся в коммунистически настроенных изданиях, привлекала именно сюжетная сторона представленных произведений. Автор статьи «Советская живопись» («Neuer Berliner Ur Zeitung» от 12.07.1930) писал, что выставку отличает «преимущественно плоскостное видение натуры, в которую введены люди не как индивидуумы, но как представители народа. Это восприятие людей, отражающее коммунистическое мировоззрение, и есть то общее, что объединяет всех русских художников и выделяет их из всего европейского художественного творчества» [4, л. 9].

Положительное отношение к СССР чувствуется и в публикации газеты «Die Rote Fahne» («Красное знамя», статья «Советско-русская живопись» от 10.07.1930), в которой выражалась симпатия к стремлениям художников «переживать и отображать социалистическую действительность Советского Союза» [4, л. 3]. После выставки в Швеции, пожалуй, лишь в газете «Новый день» был оставлен благоприятный отзыв, пронизанный пафосом и верой в пролетарскую культуру: «Русские художники непосредственно участвуют в социалистическом строительстве. Они изображают на полотнах различные этапы строительства, гигантские сооружения на Днепрострое, нефтяные вышки в Баку, новое советское земледелие. Русские художники даже организованы как обыкновенные трудящиеся, что нисколько не губит их творческие силы. Общее впечатление от этой пролетарской выставки искусства необычайно сильное. Получаешь представление о гигантских ресурсах рабочего класса. Русское искусство получает свои импульсы от борьбы рабочего класса и существует для пролетариата» [6, л. 4].

Если при оценке сюжетной стороны произведений было велико влияние политической направленности газет и журналов, то при обращении к стилистическим приемам и формальному решению композиции у критиков вставал вопрос о прямой преемственности советского искусства от художественного наследия Западной Европы. Поводом к такого рода рассуж- 
дениям является предыстория художественной жизни России на рубеже $\mathrm{XIX-XX} \mathrm{столетия.} \mathrm{В} \mathrm{этот} \mathrm{период} \mathrm{и} \mathrm{позднее} \mathrm{немало} \mathrm{русских} \mathrm{(будущих} \mathrm{со-}$ ветских) художников проходили обучение в Академиях художеств Мюнхена, Вены, стажировались в частных студиях, из которых наибольшей популярностью пользовались две - венгра Ш. Холлоши и словенца А. Ашбе. Здесь в разное время оттачивали свое мастерство И. Э. Грабарь, В. А. Фаворский, К. С. Петров-Водкин, Д. Н. Кардовский, И. Я. Билибин и другие. Шимон Холлоши весьма лестно отзывался о наших соотечественниках, «страстно верил в огромную роль, которую русскому народу предстоит выполнить в развитии человечества», объясняя это «неисчерпаемыми природными богатствами» и «обилием одаренных людей» [10, с. 52].

Культурное взаимодействие не ограничивалось одним лишь образовательным процессом. В Германии неоднократно проходили вернисажи, где русские художники выступали как с персональными, так и с групповыми выставками. Среди них мы можем назвать Берлинский Сецессион 1903 года, на котором были представлены работы M. А. Врубеля, В. А. Серова, Н. К. Рериха, Ф. А. Малявина, В. В. Кандинского и других.

Грандиозной по своему размаху стала выставка русского искусства XVIII - начала XX вв., устроенная С. П. Дягилевым сначала в Париже, а затем в Берлине в 1906 году [11, с. 15-16].

Творческие и учебные связи на рубеже XIX-XX в. в значительной мере способствовали усвоению русскими художниками стилистических приемов и техники живописи Западной Европы, что впоследствии нашло отклик и в советском изобразительном искусстве. Однако если до революции подобное влияние воспринималось как естественный процесс культурного обмена, то к 1930 г. критики ожидали от советского искусства собственных изобразительных находок и потому жестко осуждали выставки, где встречали давно знакомые приемы.

Наиболее ярко в этом отношении отреагировали периодические издания Берлина и Вены. «Neues Wiener Abendblatt» (от 05.11.1930) констатировала, что «не следовало привозить ящиков из России, чтобы показать живопись всего мира...» [5, л. 7]. «Wolks Zeitung» (от 08.11.1930) также не заметила «ничего своеобразного, ничего русского, ничего нового ни для наших глаз, ни для наших чувств» [5, л. 1-2]. От страны, где произошла революция, ожидали резких поворотов в художественной жизни и удивлялись, когда этого не происходило. В «Neues Wiener Journal» (от 01.11.1930) автором статьи о выставке указывалось: «Социальные потрясения в России очень мало воздействовали на искусство. Русское искусство сегодня - это изобразительное искусство всего мира» [5, л. 3].

С 20 марта по 15 апреля выставка советского искусства проходила в Стокгольме и, по свидетельству ВОКС, «привлекла тысячи посетителей и встретила живой отклик в шведской прессе» [6, л. 2]. Но и здесь критики «укололи» фрранцузским влиянием (издание «С.А.Ф.». Статья от 22.03.1930): «О новой эре все эти картины свидетельствуют больше своими темами 
Бакарягин С. С.

и пронизывающим их духом, чем своим художественным стилем, ибо новая форма еще не созрела. Сильно заметно влияние Парижа» [6, л. 5-6].

Если Россия еще до революции была связана с Германий и Австро-Венгрией достаточно тесными культурными отношениями, то со Швецией таких прочных контактов установлено не было. Последняя значительная выставка русских художников проходила в Мальмэ в 1914 г. и была прервана войной. Это обстоятельство, в свою очередь, повлияло и на критиков. Если Берлин и Вена рассматривали выставку в контексте сложившейся традиции, то в Стокгольме перед глазами была выставка 1914 г. как своего рода наглядный образец для сравнения. Картины, заполнившие пространство галереи в 1930 г., по мнению критика Э. Розенберга, имели «весьма отдаленное и убогое родство с теми художественными произведениями. Красочная шкала снижена, исчезла техническая уверенность. В формальном отношении искусство революционной России гораздо менее революционно, чем искусство царской России. Советское правительство, очевидно, стремится вырастить своего рода коммунистический академизм» [6, л. 3].

Приведенные выдержки из периодической печати не являются исчерпывающими. Они вполне умеренные, не проявляющие восторга в отношении искусства СССР. Важно также, что критики могли высказывать неудовлетворенность экспозицией, указывали на ее тенденциозность и в то же время отмечали мастеров, чьи произведения, по их мнению, выделялись из общего ряда. Среди таковых назывались имена Ю. И. Пименова, Р. Р. Фалька, С. А. Лучишкина, Е. С. Зерновой, А. Ф. Пахомова, М. Л. Гуревича, В. В. Лебедева и других художников [4-5].

Наибольшую популярность у западноевропейской прессы снискали мастера «старой» школы: А. Е. Архипов, И. Э. Грабарь, К. С. Петров-Водкин. В «Morgenpost» (статья «Новое русское искусство» от 09.07.1930) говорилось следующее: «Архипов с его радостно-пестро, сильно, ярко и крепко написанной "Крестьянкой Рязанской губернии”, примыкающий к еще довоенным традициям, имеет мужество продолжать линию своего искусства [...]. Ему противоположено совсем современное произведение Петрова-Водкина “Землетрясение в Крыму”, произведение внутренней правдивости и большого значения фригурной композиции [...]. Игорь Грабарь [...] выказывает многосторонность и живописную интенсивность, что делает его работы одними из самых интересных на выставке» [4, л. 4]. Если зафиксировать количество положительных отзывов о художниках, то самым авторитетным и часто упоминаемым среди них был Абрам Ефимович Архипов (1862-1930). «Neues Wiener Extrablatt» (от 01.11.1930) гласила: «Архипов, один из немногих, темы которого веселы и радостны. Его смеющиеся крестьянские девушки освежающе воздействуют на посетителя» [5, л. 4]. Автор в «Reichspost» (статья «Современное русское искусство» от 31.10.1930) был еще более категоричен в хорошем смысле слова: «Единственный художник, живописно сильный, Архипов, был выдающимся мастером еще в дореволюционную пору [...]. Только в графике и крестьянской скульптуре Ефи- 
мова и Сандомирской чувствуется настоящее мастерство и видны попытки самостоятельного творчества» [5, л. 3].

Графика и скульптура на выставке в целом были встречены критикой гораздо более благоприятно по сравнению с живописью.

Три выставочных проекта СССР 1930 г. в большинстве своем не имели успеха в зарубежной прессе. От молодого государства, строящего коммунизм и воспитывающего человека нового типа, авторы публикаций ожидали новых проявлений в изобразительном искусстве. Изначально Советская власть лишь присматривалась к различным творческим объединениям в стране и старалась радикально не вмешиваться в художественную жизнь, но уже к началу 1930-х гг. идейная направленность будущего советского искусства была определена и бесплодные, с точки зрения власти, творческие искания были решительно пресечены.

Немалое влияние на характер рецензий имела политическая направленность периодических изданий. Так, в обращении к сюжетам из окружающей жизни кто-то находил смысл искусства, достойный страны Советов; кто-то, напротив, не видел в них ничего оригинального. Оценивая стилистику представленных произведений, критики отмечали ее прямое родство с западноевропейской традицией. Пожалуй, лишь графические и скульптурные работы были встречены благосклонно и признаны действительно оригинальными и в чем-то даже самобытными.

\section{Ссылки}

1. Урядова А. В. Выставочная деятельность русской эмиграции в первой половине ХХ в. // Новейшая история России. 2019. Т. 9, № 2. С. 485-500.

2. Государственный архив Российской Федерации (ГАРФ). Ф. 5283. Оп. 1. Д. 1. Л. 1-2.

3. Киселева Н. В. Общество культурных связей с зарубежными странами $(\mathrm{BOKC)} \mathrm{в} \mathrm{борьбе} \mathrm{за} \mathrm{прорыв} \mathrm{культурной} \mathrm{блокады} \mathrm{СССР} \mathrm{//} \mathrm{Государство,} \mathrm{общество,}$ церковь в истории России XX-XXI веков: материалы XVI Международной коноеренции: в 2 ч. Иваново, 5-6 апреля 2017 г. Иваново, 2017. С. 57-61.

4. Российский государственный архив литературы и искусства (РГАЛИ). Ф. 2941. Оп. 1. Д. 115.

5. РГАЛИ. Ф. 2941. Оп. 1. Д. 116.

6. РГАЛИ. Ф. 2941. Оп. 1. Д. 117.

7. РГАЛИ. Ф. 2941. Оп. 1. Д. 99.

8. Луначарский А. В. Об искусстве. Т. 2: Русское советское искусство. М., 1982. $391 \mathrm{c.}$

9. АХРР: Сборник воспоминаний, статей, документов / сост. И. М. Гронский, В. Н. Перельман. М., 1973. 503 с.

10. Тихомиров А. Н. Искусство Венгрии IX-XX вв. М., 1961. 187 с.

11. Толстой А. В. Художники русской эмиграции. М., 2005. 344 с. 